MATEC Web of Conferences 17, 01013 (2014)

DOI: $10.1051 /$ matecconf/ 20141701013

(C) Owned by the authors, published by EDP Sciences, 2014

\title{
Anchor Fitted with Special Fin for Soil Reinforcement
}

\author{
A.N. Abdul Ghani ${ }^{1, \text { a }}$, M.F.Z. Alias ${ }^{2}$ \\ ${ }^{1,2}$ School of Housing, Building and Planning, Universiti Sains Malaysia, 11800, Penang, Malaysia
}

\begin{abstract}
In order to ensure that anchored soil retention systems are more stable and free from failure, suitable anchors are required. A new technique using anchors with fins were investigated, particularly for mechanically stabilized earth. An experimental laboratory investigation on the behaviour of anchors with fins by using various shapes, sizes, arrangements and lengths were presented. The main purpose of this study is to investigate the load-displacement relationship of pullout anchors with fins embedded in sand. A rectangular model tank with dimensions $0.6 \mathrm{~m}$ length, $0.5 \mathrm{~m}$ width and $0.3 \mathrm{~m}$ high was designed. Models of 15 types of anchors of different lengths $(0.3 \mathrm{~m}, 0.4 \mathrm{~m}$ and $0.5 \mathrm{~m})$ with fins using different and various types of lengths, sizes and arrangements embedded in sand, were experimented with . The testing program included 45 tests embedded in dry sand. The experiment was conducted in a soil laboratory at a scale of 1:10. The fin was placed at the end of the anchor shaft that abuts the failing structure which prevents further movement. It was concluded that the size, shape and angle of the fin influenced the pullout capacity of the anchor. Finally, selected anchors were recommended based on their superior performance.
\end{abstract}

\section{Introduction}

Ground anchor is a device that is designed to support structures and used in geotechnical and construction applications, especially in retaining wall construction. Anchoring systems are used extensively in civil engineering practices to provide resistance against pullout forces and overturning moments. Anchors are manufactured in a variety of configurations such as plate anchors, pile anchors, pre-stressed concrete anchors and grouted anchors [1]. Ground anchors constitute a versatile system that, if properly used, can offer advantages in ground engineering [2]. Advancements in the design and construction of large retaining walls have transformed civil engineering practices in the last 40 years. Unfortunately, the risks associated with large retaining walls have grown faster than the development of new designs. In particular, some reports estimate that mechanically stabilized earth walls fail at an alarmingly high rate of about 1 in every 1,000. This high failure rate has led to frequent litigation and has caused many design engineers to avoid projects with large retaining walls [3].

Nowadays, retaining walls are of great design. However, the forces of nature and the laws of physics can work against even the best engineered retaining wall. These forces can cause catastrophic failure. There are three ways retaining walls can fail which is the overturning, sliding and settlement of foundation. Overturning is caused by the force of the soil pushing a wall over when the thrust exceeds the wall's weight [4]. The sliding failure along the base of the gravity retaining wall and the

\footnotetext{
${ }^{\mathrm{a}}$ Corresponding author : anaser@usm.my
} 
rotational failure of the active soil wedged behind the wall, as well as the rotational failure of the slide mass of the anchor-reinforced slope were considered in the present formulation [5]. Therefore, the installation of anchors can reduce the failure of the retaining wall. For the specific characteristics of the analysed fill slopes and the input of the horizontal ground motion, the slope reinforced with anchors appeared to experience vertical and horizontal seismic displacements. Figure 1 shows the installation of anchors and Figure 2 demonstrates the ground anchor.

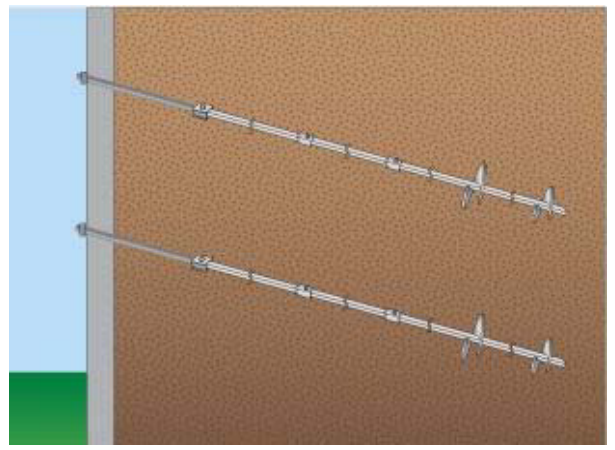

Figure 1: Installation of anchors

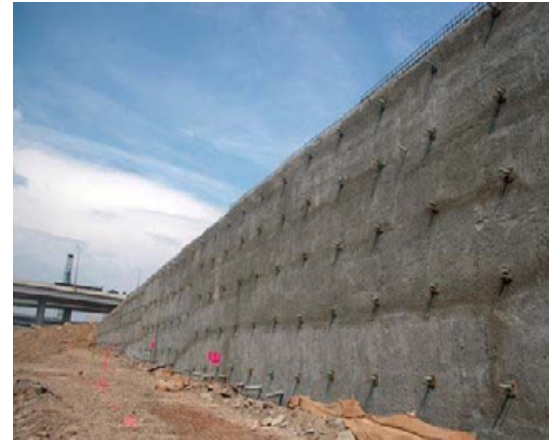

Figure 2: Ground anchor

\section{Experimental Investigations}

In this research, the process of collecting data was a laboratory experiment. In the first stage, a rectangular model tank, $0.6 \mathrm{~m}$ long, $0.5 \mathrm{~m}$ wide and $0.3 \mathrm{~m}$ high was designed. At the next stage, models of 15 types of anchors with fins using different and various types of lengths, sizes and arrangements were designed. The models were designed so that the effect of the size and shape of the fin on the anchor performance in the pullout could be studied. A preliminary test was conducted before doing an actual test. The model tank was made up of mild steel square box sections, plywood, pulley, string and reinforcement steel bar, whilst the anchor was made up of steel plates and reinforcement steel bar R12. The instruments used in this experiment were a data logger, load cell, Linear Variable Displacement Transducer (LVDT) and magnetic base. The test was set up as in Fig. 3.

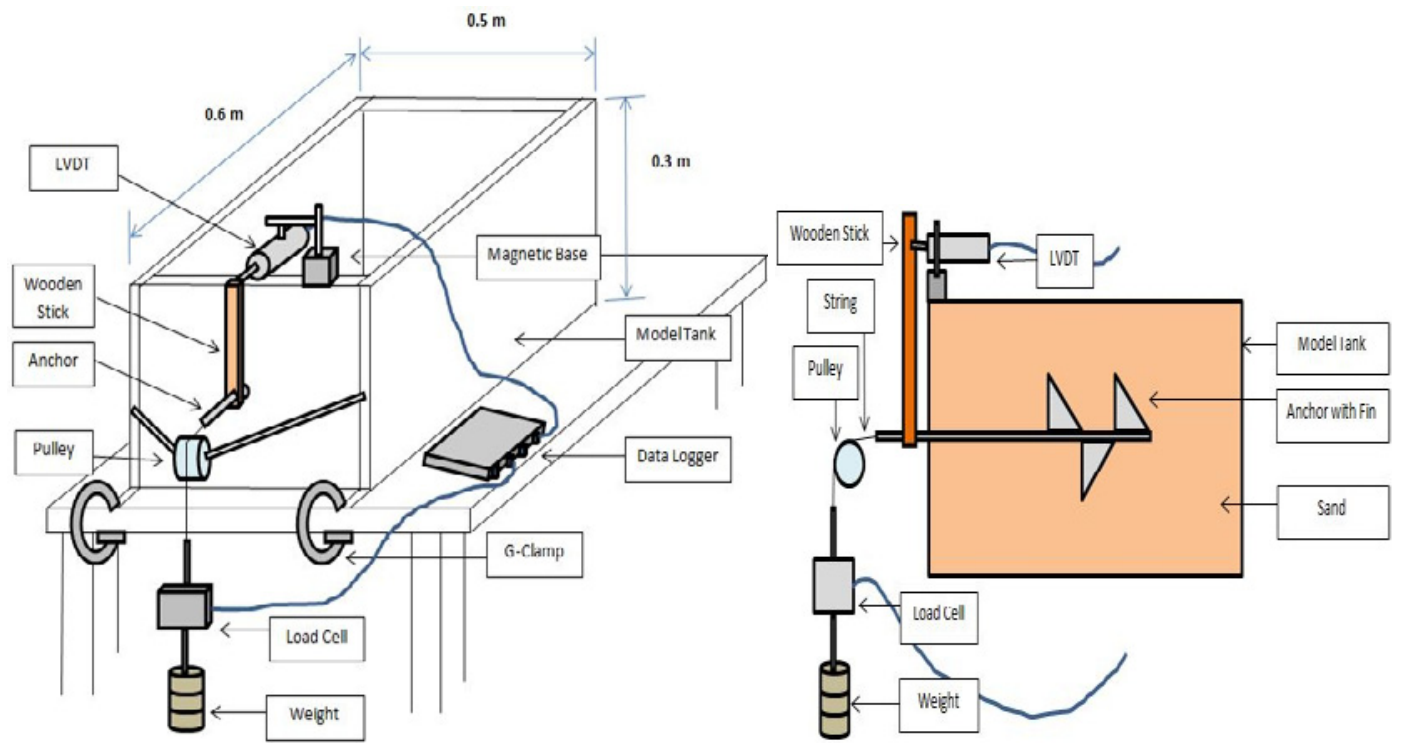

Figure 3: Test setup

Figure 4: 2D diagram 
A rectangular model tank was set up and fixed on the table using a G-Clamp. Figure 5 shows the dry sand $(300 \mu \mathrm{mm}$ in size after being sieved) which was put into a model with about $150 \mathrm{~mm}$ depth. An anchor with a length of $500 \mathrm{~mm}$ embedded in sand was inserted into a small hole in front of the model as shown in Figure 6. Then, the dry sand was again put into the model until full. The dry sand needed to be compacted first before starting the experiment. A small wooden stick which was already drilled prior to the experiment was inserted into the anchor hole before the anchor was tied with the string. The wooden stick will move in line with the anchor when the forces act on it. A long string was cut into $220 \mathrm{~mm}$ lengths. The string was tied on the anchor hole and was connected to the load cell.

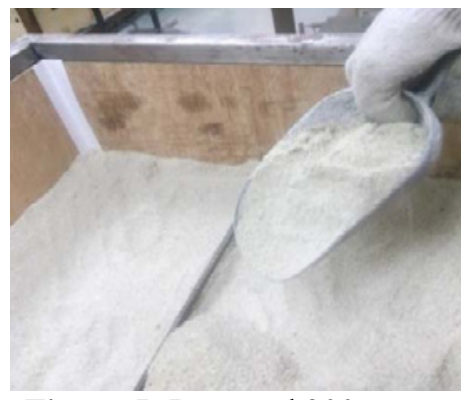

Figure 5: Dry sand $300 \mu \mathrm{mm}$

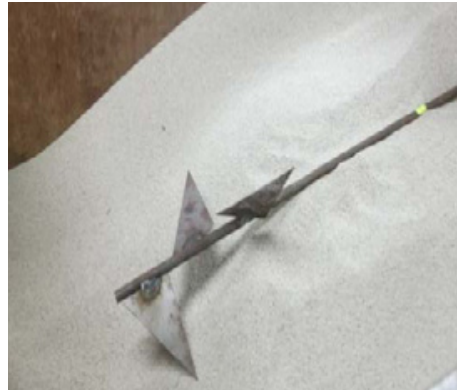

Figure 6: Anchor was inserted

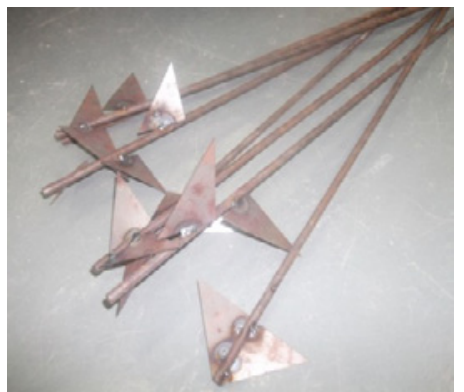

Figure 7: Model of anchor

A load cell was used to measure the forces that act on the anchor. A Linear Displacement Variable Transducer (LVDT) was placed on top of the model and was stood by using a Magnetic Base. The LVDT needs to be in contact with the wooden stick. A magnetic fixture based on magnets that can effectively be turned 'on' and 'off' at will was fixed. It was placed on the steel frame of the model to hold the LVDT. The LVDT was used to measure the displacement of the anchor when forces act on the anchor. Both the load cell and the LVDT cables were connected to the Data Logger (KYOWA) and connected directly to a laptop. KYOWA UCAM-70A software was used to analyse the data. It is an electronic device that records data over time and records signals from the load cell and the LVDT.

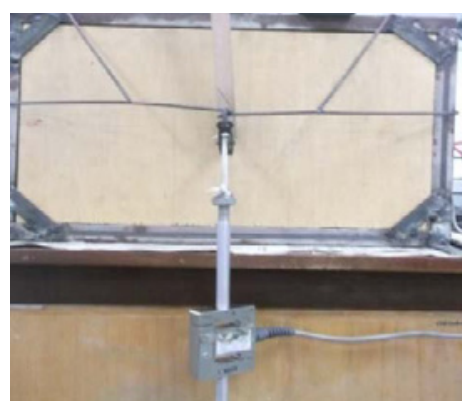

Figure 8: Load Cell

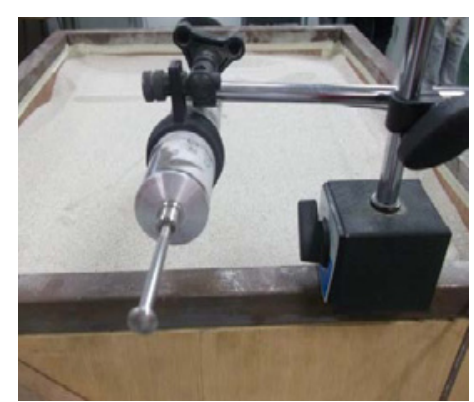

Figure 9: LVDT

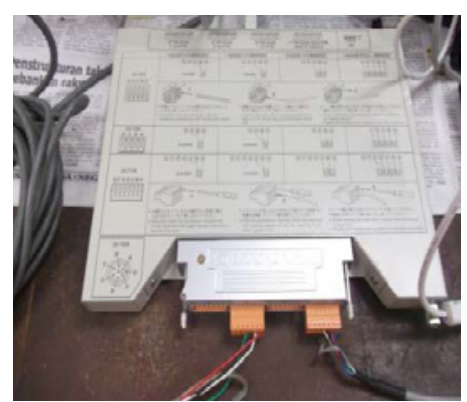

Figure 10: Data Logger

Figure 11 shows weights $(1 \mathrm{~kg})$ placed one by one on the load cell every 5 seconds up till $15 \mathrm{~kg}$. The anchors were tested with $15 \mathrm{~kg}$ of weights until they failed. When the forces were applied to the anchor, the anchor will move in tandem with the wooden stick as well as the in- contact LVDT. Figure 12 shows the readings of force and displacement of the anchor recorded. Then, weights $(16 \mathrm{~kg}$ and 32 $\mathrm{kg}$ ) were placed on top of the sand with repetition of steps 2 to 14 to test the performance of the anchors with different pressure. After the test was done, all the dry sand was removed and it was put in a container. Steps 2 to 16 were repeated using 15 various types, shapes and arrangements of the anchors, 3 different lengths of anchors embedded in sand $(300 \mathrm{~mm}, 400 \mathrm{~mm}$ and $500 \mathrm{~mm})$ and different weights that act on the anchors. Figure 13 shows the different sizes of anchors and Figure 14 shows the different design and pattern of anchors. 


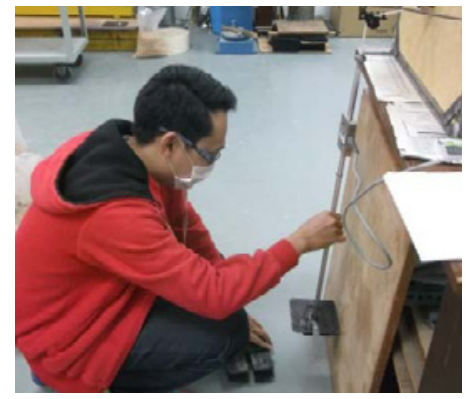

Figure 11: Weight was placed on load cell

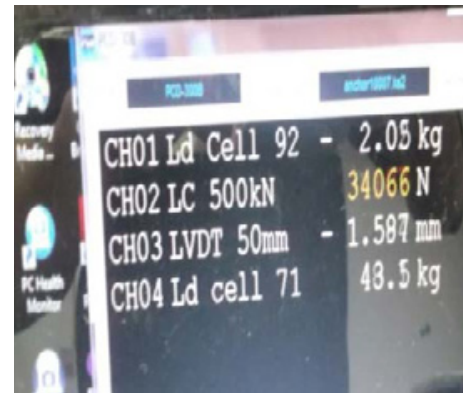

Figure 12: Force and displacement were recorded
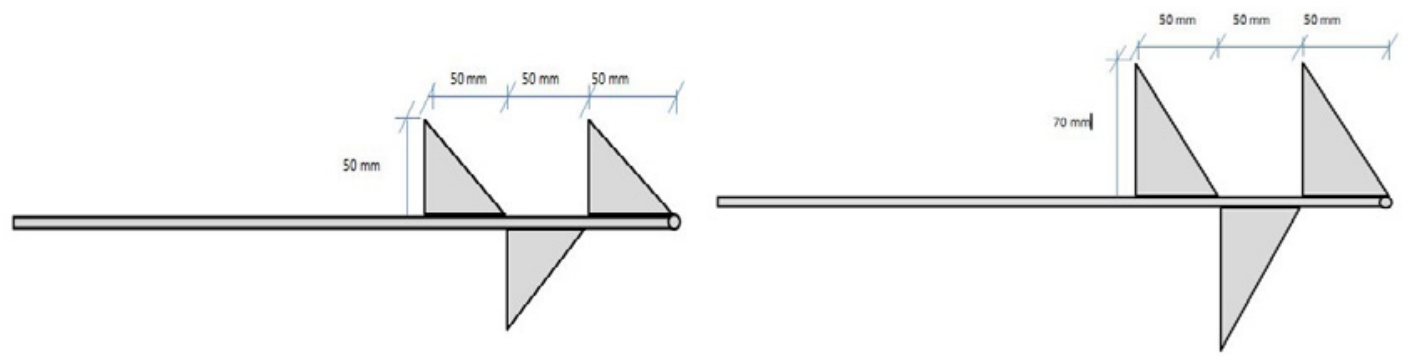

Figure 13: Different sizes of anchors

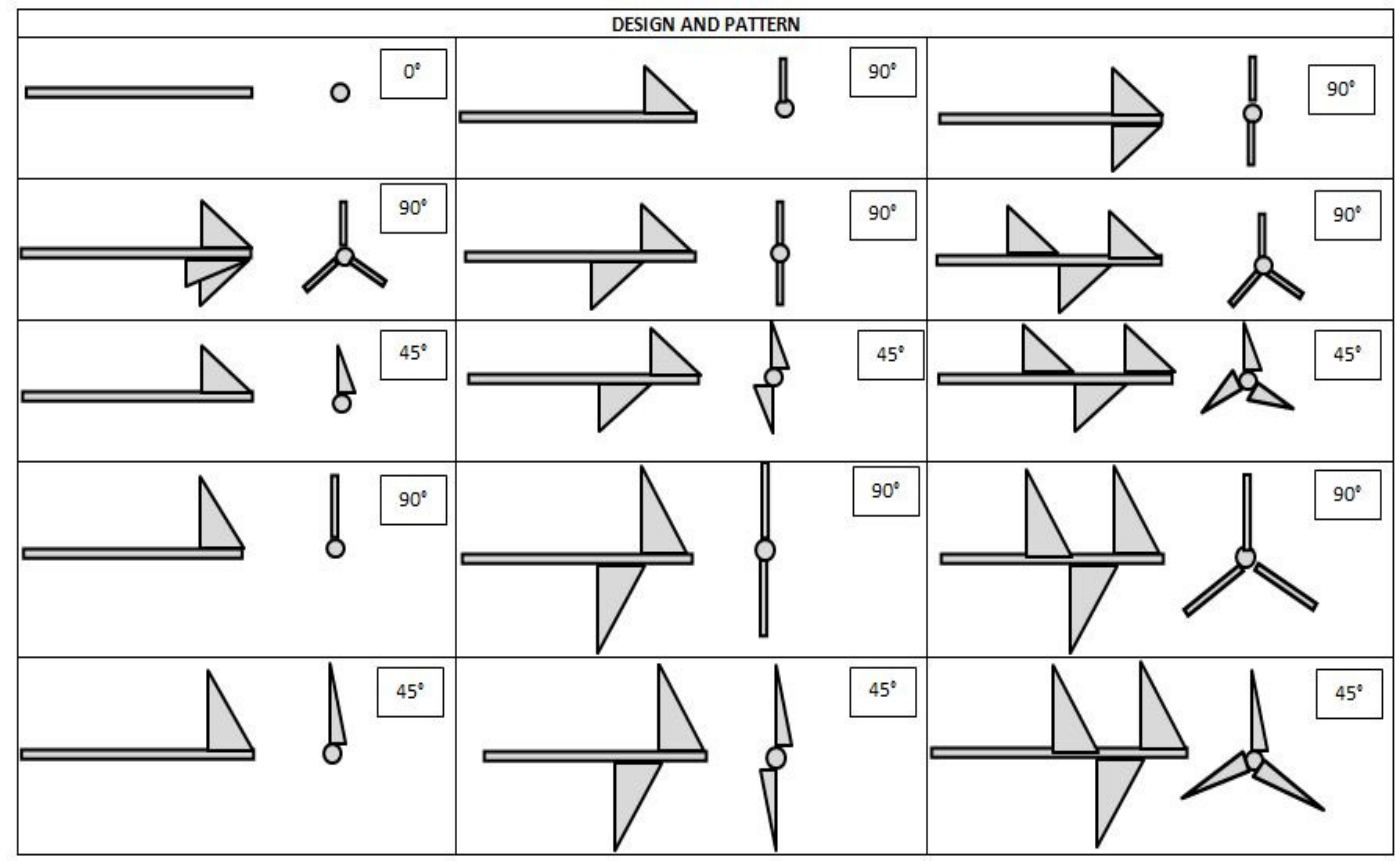

Figure 14: Design and pattern of anchors

\section{Results and Discussion}

The embedded length of the anchor is one of the key parameters because in practice it is varied until it reaches the optimum. The load-displacement relationship which is the relationship between the 
ultimate pullout load and the length of the anchors embedded in sand is shown in Figure 15 for the fifteen models of anchors tested in this investigation.

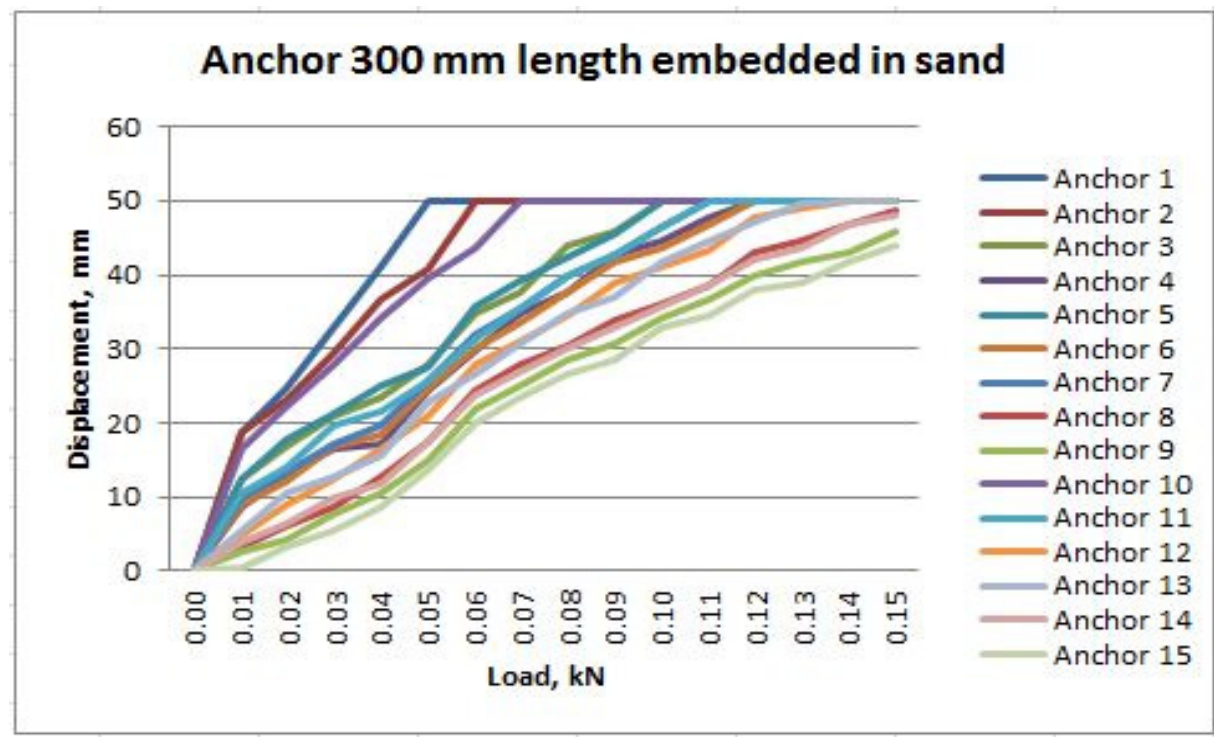

Figure 15: Load-Displacement relationship

Based on Figure 12, four anchors have no fail when a load of $15 \mathrm{~kg}$ was applied. Anchor 15 shows less movement in the sand, followed by Anchor 9, Anchor 14 and Anchor 8. The remaining 11 anchors have failed and show more movement when the load was applied. The anchors were tested for $300 \mathrm{~mm}$ lengths embedded in sand. This experiment was carried out to compare the anchors in parametric. The scale of the model in this experiment is $1: 10$. At $5 \%$ (15 mm displacement), which is equal to $150 \mathrm{~mm}$ movement in real scales, it shows the consistency with respect to increasing movement forms of all anchors. At 10\% (30 mm displacement), equivalent to $450 \mathrm{~mm}$ movement in real scales, it shows some inconsistency of movement forms. At $15 \%$, equivalent to $450 \mathrm{~mm}$ movement in real scales, it also shows some inconsistency of movement forms. Although the structure is not a failure, the results show the change of movement forms.

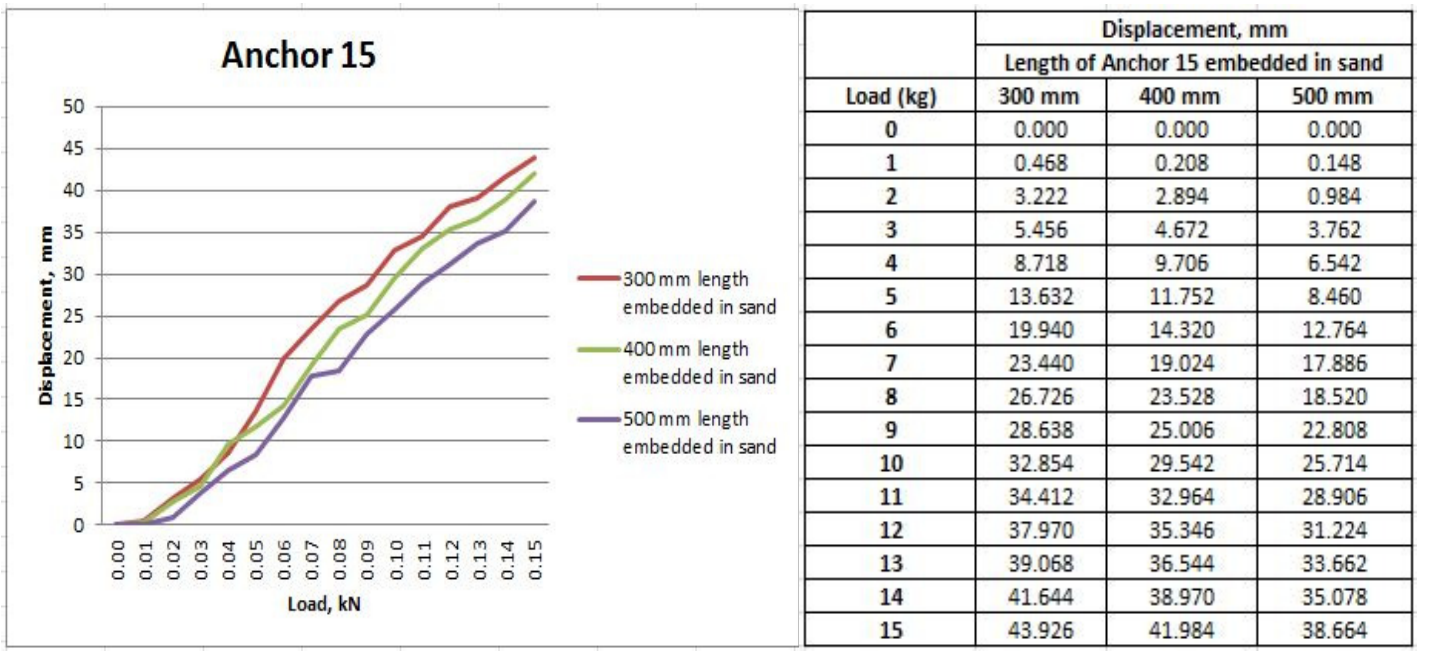

Figure 16: Load-Displacement relationship of Anchor 15 


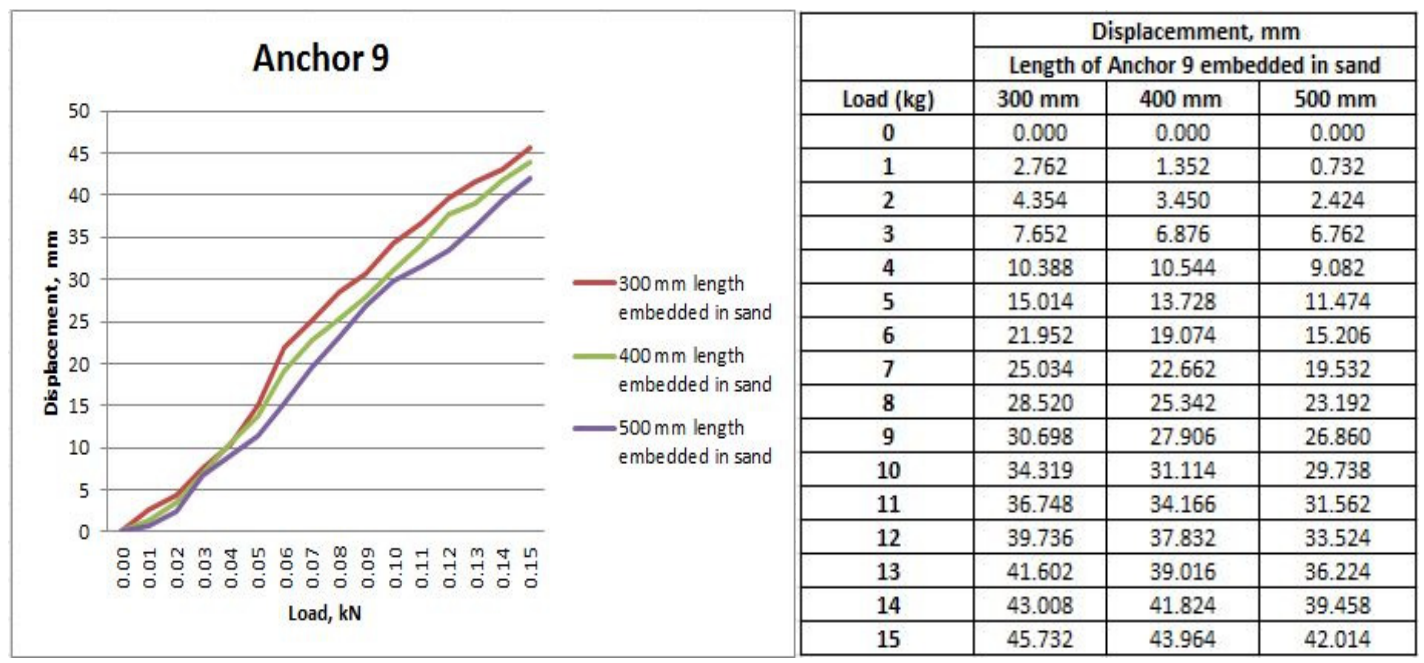

Figure 17: Load-Displacement relationship of Anchor 9

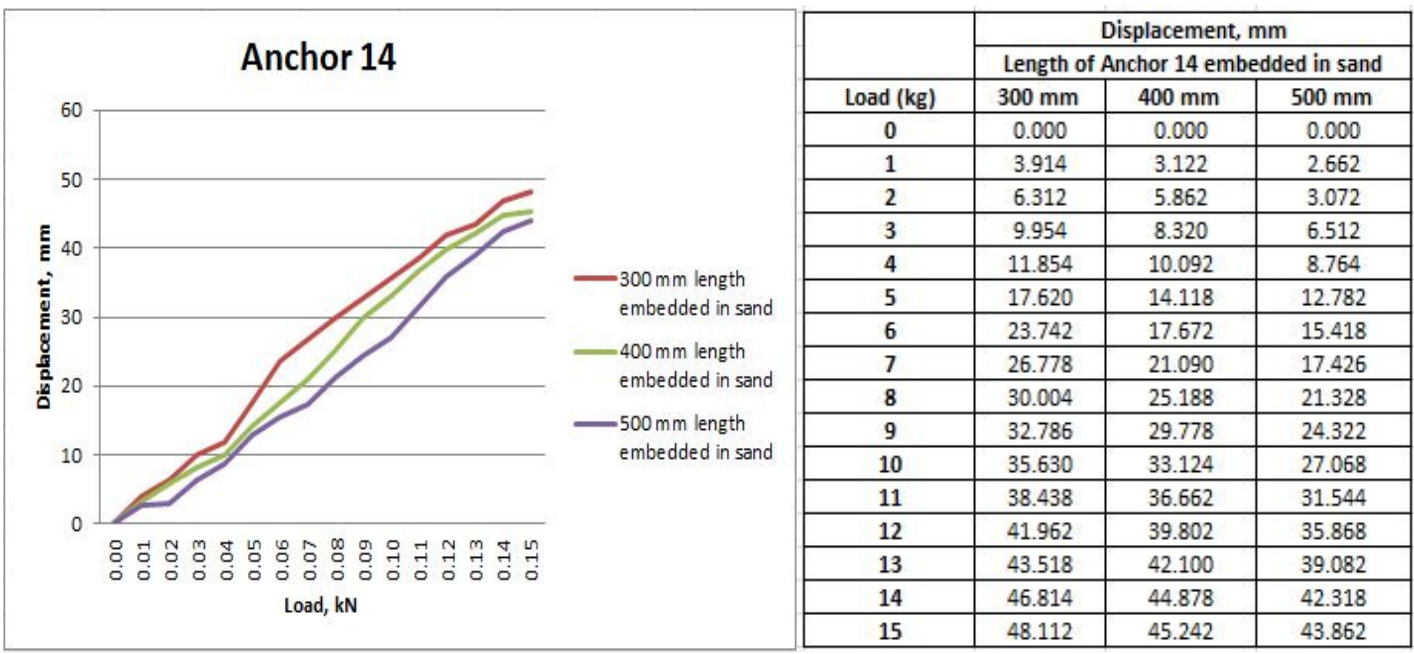

Figure 18: Load-Displacement relationship of Anchor 14

Figures 16 to 18 show the load versus displacement for Anchors 15, 9 and 14 embedded in sand with 3 different lengths which are $300 \mathrm{~mm}, 400 \mathrm{~mm}$, and $500 \mathrm{~mm}$. It can be clearly seen that all anchors have no failure, although they were installed in 3 different lengths. These figures show a significant increase of the peak pullout forces and a larger displacement until the peak, and consistent movements towards the anchor form. The length of the anchors embedded in sand can influence the movement towards the anchors, which is the longer the anchor that is embedded in the sand, the less movement would occur.

Among the three best anchors, Anchor 15 shows the best results compared to Anchor 9 and Anchor 14. Both Anchor 15 and Anchor 9 have three fins, whilst Anchor 14 has two fins. All of the anchor fins were welded at $45^{\circ}$, so the anchor will be stable and strong because the area of fins will be more in contact with the sand. In actual scales, the surface area of Anchor 15 is larger than Anchor 9 and Anchor 14. The surface area of fins that are in contact with the sand will influence the strength of anchors. 


\section{Conclusions and Recommendation}

The pullout behaviour of the anchors in the sand depends on several factors which are sizes, shapes and numbers of fins on the anchor, degree of fin arrangement, length of the anchors embedded in sand, the angle of shearing resistance of the soil, and load applied to the earth anchors. The more fins installed at an anchor, the stronger the retaining wall is anchored. The more surface area of fins in contact with the sand, the stronger the anchored wall. The longer the distance of the anchor embedded in ground earth, the more stable the anchored retention systems are. Based on the experimental investigation, three model anchors out of 15 anchors, Anchor 15, Anchor 9 and Anchor 14 were proven to be the most suitable to prevent further overturning movement. Figure 19, Figure 20, and Figure 21 show the anchor models that gave more strength, less movement and did not fail when the forces acted on it.
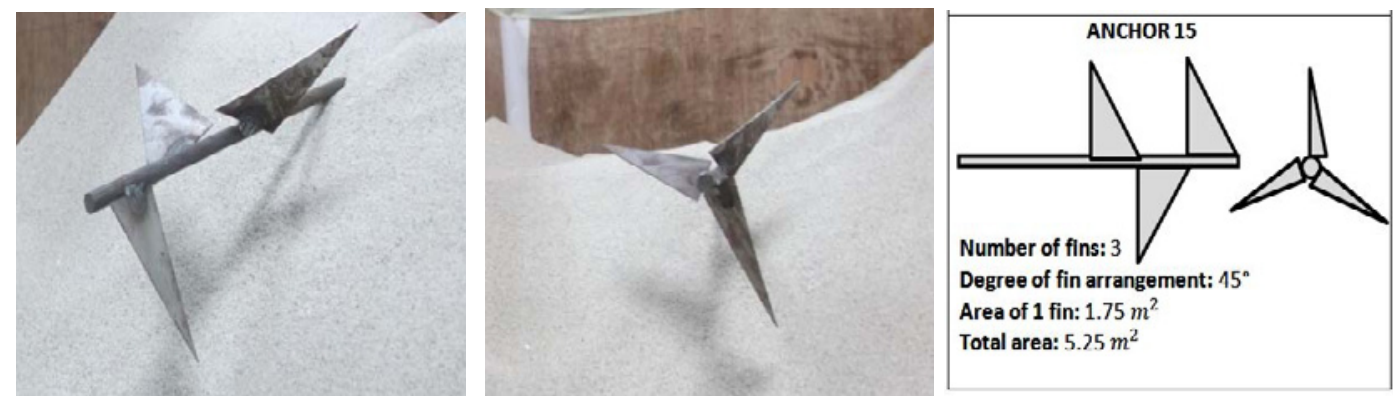

Figure 19: Design and pattern of Anchor 15
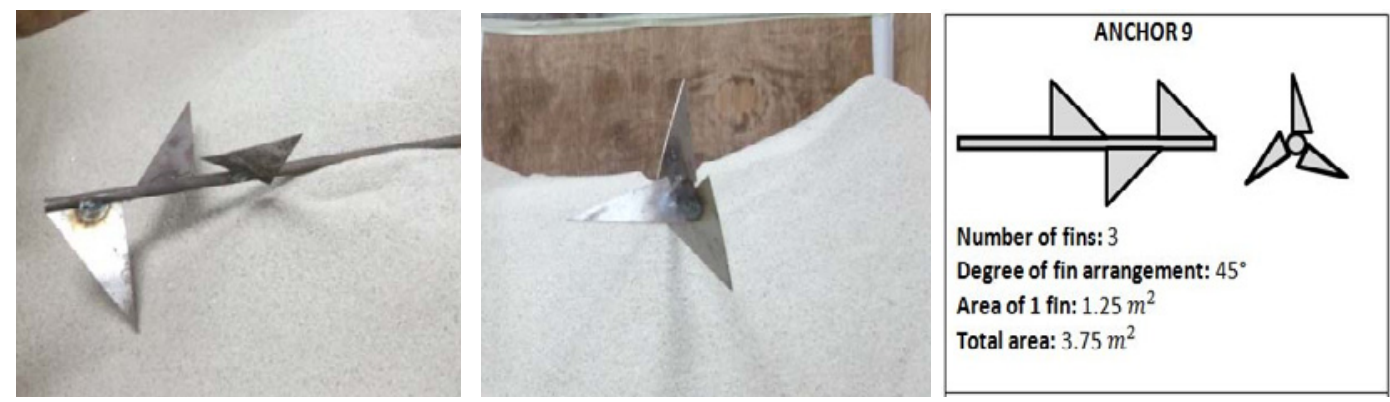

Figure 20: Design and pattern of Anchor 9
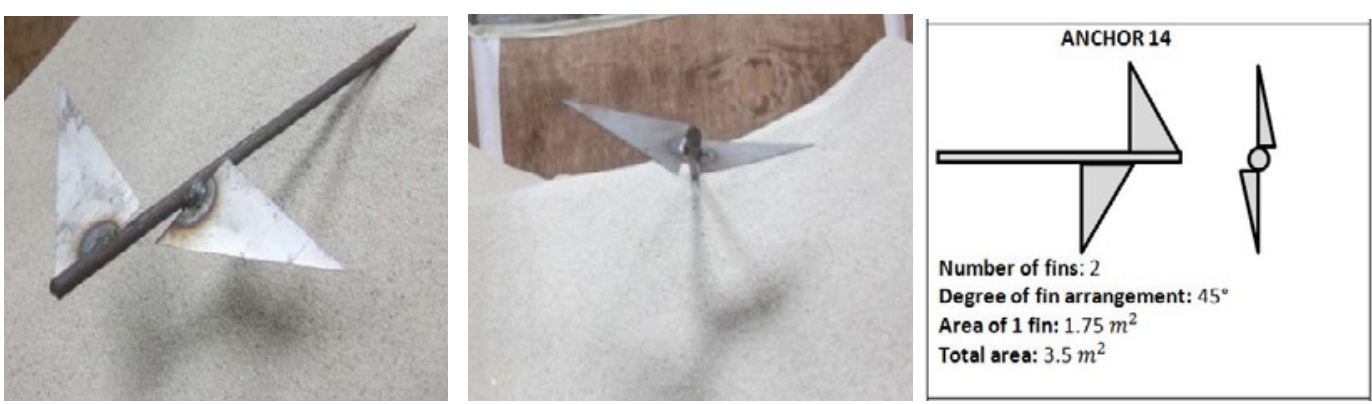

Figure 21: Design and pattern of Anchor 14

It is recommended that the study uses numerical models to predict the pullout capacity of anchors with different inclination angles in various types of soil parameters such as dry sand, silt and clay. Other than that, a study on the techniques of placing the anchor into existing soil and slope is also recommended. A full scale study might help to validate this concept. 


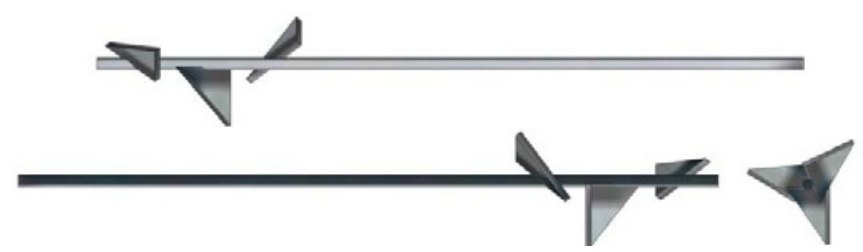

Figure 22: Illustration of best anchor with fin
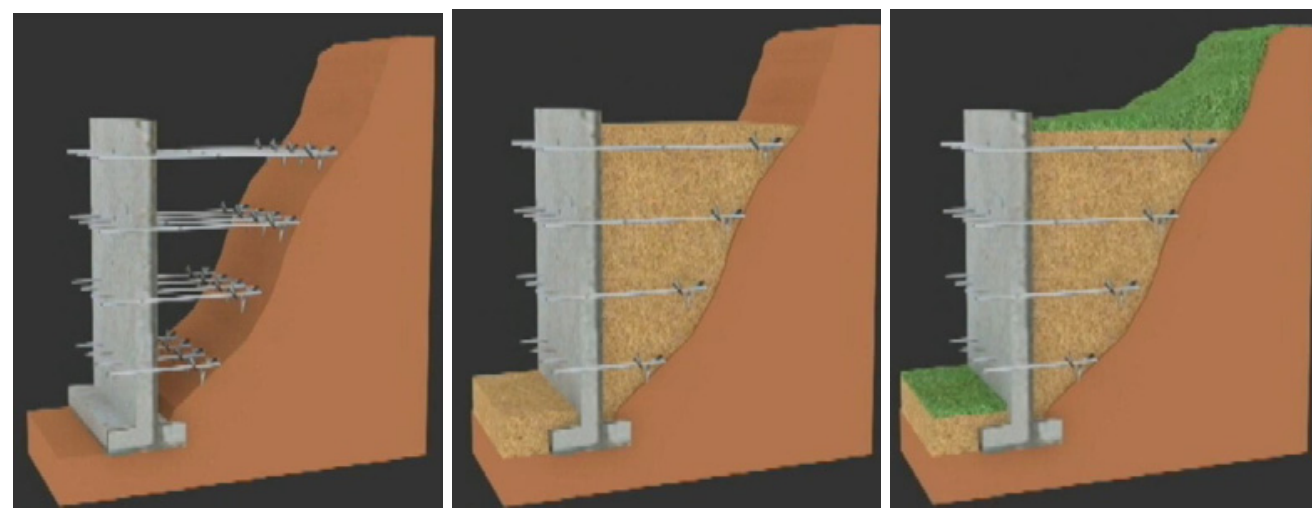

Figure 23: Possible application of anchor with fin in actual construction

Figure 23 shows the possible installation process of reinforced soil wall anchors with fins. The anchors were embedded in soil slopes and the backfill soil was placed behind the retaining wall. The anchors can only be applied to filling soil, not an existing slope. The sand needed to be compacted first. The application of anchors with fins could help to improve the stability of the wall and prevent overturning movements.

\section{Acknowledgement}

The authors would like to acknowledge partial financial support for this study by research grant no. 203/PPBGN/6711257 provided by USM/MOE Malaysia.

\section{References}

1. Regenass, P. and Soubra, A. H. 1997. Limit Loads of Strip Anchors, International Conference Institutions of Civil Engineer, p. 109-118.

2. Xanthakos, P. P. 1991. Ground Anchors and Anchored Structure, 1991.

3. Steve Wendland, When Retaining Walls Fail, http://cnews.com/article/8330/when-retainingwalls-fail, June 2011.

4, John Denson, Three Reasons Why Retaining Walls Fail, http://www.cselandscapearchitect.com /three-reasons-why-retaining-walls-fail, April 2013.

5. Trandafira, A. C., Kamaib, T. and Sidlec, R. C. 2009. Earthquake-induced displacements of gravity retaining walls and anchor-reinforced slopes, Dynamics and Earthquake Engineering, 29 (3), p. 428-437. 